\title{
EVOLUÇÃO CONCEITUAL DE PROFESSORES SOBRE O MOVIMENTO DIÁRIO DA ESFERA CELESTE
}

\author{
Conceptual evolution of teachers \\ about the daily motion of the celestial sphere
}

\author{
Paulo Sergio Bretones ${ }^{1}$ \\ Maurício Compiani ${ }^{2}$
}

\begin{abstract}
Resumo: Este é um estudo sobre a elaboração do conceito de movimento diário da esfera celeste por um grupo de professores de Ciências e Geografia de $5^{a}$ a $8^{a}$ séries, participantes de um curso de Astronomia. Os resultados baseiam-se, sobretudo, na análise de suas respostas às perguntas das avaliações e em registros de aulas do curso. Discutem-se: a relação entre as respostas dos participantes, seus relatos sobre suas observações, e o desenvolvimento de conteúdos referentes ao movimento de constelações. Apresentam-se as elaborações de sequências da evolução conceitual do grupo e sua relação com a prática e a teoria trabalhadas no curso. Tais elaborações revelam os princípios relacionados à observação do céu: relação da altura do polo celeste com a latitude geográfica, obliquidade, continuidade do movimento, circularidade, tridimensionalidade e ciclicidade. $\mathrm{O}$ estudo sugere que esses princípios, usados como guias heurísticos, seriam úteis para o ensino da observação do céu.
\end{abstract}

Palavras-chave: Astronomia. Formação de professores. Evolução conceitual. Ensino de ciências.

\begin{abstract}
This work presents a study about the concept formation of the daily motion of the celestial sphere by a group of middle school teachers participants of an Astronomy course. The results are based on the analyses of the answers of these teachers for the questions made in the check tests and the records from the classes of the course. It is studied the relation between the answers, the accounts of the sky observations by the participants and the development of the contents about the daily motion of the celestial sphere. The elaborations of sequences of the verified conceptual evolution by the group and its relation with the theory develop in the course are presented. After a closer look at the elaborations of the participants, some principles were revealed: the elevation of the celestial pole to geographic latitude, obliquity, continuity of motion, circularity, tri-dimensionality and cyclicity. The study suggests that these principles shoud be used as heuristic guides, suitable for the teaghing of sky observation.
\end{abstract}

Keywords: Astronomy. Science education. Teacher education. Conceptual evolution.

\footnotetext{
${ }^{1}$ Graduado em Química, doutor em Ciências. Docente, Departamento de Metodologia de Ensino, Universidade Federal de São Carlos. São Carlos, SP, Brasil. <bretones@ufscar.br>

${ }^{2}$ Graduado em Geologia, doutor em Educação. Docente, Departamento de Geociências Aplicadas ao Ensino do Instituto de Geociências, Universidade Estadual de Campinas. Campinas, SP, Brasil. <compiani@ige.unicamp.br>

${ }^{1}$ Universidade Federal de São Carlos

Via Washington Luiz, Km 235

Caixa Postal 676

São Carlos, SP

735

13.565-905

Ciência छ̊̀ Educação, v. 17, n. 3, p. 735-755, 2011
} 


\section{Introdução}

Com base na análise dos conceitos apresentados nas avaliações de um grupo de alunos-professores sobre o tema da Observação do Céu em um curso de Astronomia, discute-se a existência de princípios norteadores das relações entre a observação do céu e suas representações bidimensionais, que constituem as próprias compreensões dos fenômenos astronômicos observados.

Lanciano (1989) já afirmara que a observação direta do céu, de seus objetos e de seus fenômenos é fundamental e insubstituível. Porém, o que está colocado para esse tema como ensino vai mais além, pois necessitamos compreender a importância das observações da natureza e de suas representações para o aprendizado, conforme Compiani e Carneiro (1993) trataram, em relação ao ensino de Geologia.

Nesse contexto, esses autores, ao abordarem as reflexões para uma aprendizagem construtivista, assinalaram que

[...] uma das funções básicas da atividade educadora é a análise da realidade em busca de integrá-las aos conhecimentos pessoais, aos conhecimentos sistematizados pelas Ciências. Nessa análise as reflexões para uma aprendizagem significativa encontram nas atividades de campo um papel pedagógico fundamental, pois o campo é o contexto da aprendizagem onde '... conflito entre o real (o mundo), o exterior e o interior, as idéias, as representaçoes, ocorre em toda a sua intensidade' (PASCHOALE apud COMPIANI, 1991, p. 91, grifo nosso) (sic). Essa citação coloca em dúvida a noção de que o pensamento reflexivo só tem lugar após um certo acúmulo de informações. Em nossa opinião, a afirmação destaca que as atividades de campo facilitam uma aprendizagem construtivista. (COMPIANI; CARNEIRO, 1993, p. 91)

Nesse conflito entre o exterior (o céu) e o interior (representações), este trabalho procura discutir a utilização de modelos e representações do Movimento Diário da Esfera Celeste $(\mathrm{MDEC})^{3}$ para orientar as observações do céu e vice-versa.

Ao se estudarem, com detalhes, as elaborações conceituais de um grupo de professores, considerou-se a evolução conceitual, como proposto por Moreira e Greca (2003). Para estes autores, é preferível usar o termo "evolução conceitual", em vez de "mudança conceitual". Afirmam que

[...] provavelmente, [...] é hora, [...] de abandonar a "mudança conceitual". É tempo de perceber que evolução, desenvolvimento, enriquecimento conceitual e discriminação de significados são idéias mais pro-

\footnotetext{
${ }^{3}$ MDEC - movimento diário da esfera celeste, movimento aparente diário da esfera celeste ou movimento diurno da esfera celeste.
} 
missoras porque não implicam mudança de conceitos ou de significados. Por outro lado, elas implicam em aprendizagem significativa. Ou seja, como as concepções alternativas resultam de aprendizagem significativa, a evolução destas concepções desde "misconceptions" até "richconceptions", como propõe Schuster (1993), só pode resultar de estratégias de aprendizagem significativa. Dar novos significados (e, talvez, novos rótulos) para o conceito de mudança conceitual e a conseqüente mudança de direção nos esforços de investigação pode ser a mais promissora perspectiva para futuras investivações no campo da aprendizagem de conceitos! (MOREIRA; GRECA, 2003, p. 312, tradução nossa)

Da mesma forma, Cordero (2002) explica:

Acredita-se que o conhecimento deve ser construído pelo indivíduo, a partir das idéias que possui, baseadas na sua experiência com o mundo e com os outros. Pensa-se que essas idéias prévias, assim como as atitudes e os hábitos, se encontram fortemente estruturadas. Fala-se da aprendizagem como "evolução conceitual", pretendendo desta forma superar a concepção de substituição afirmada pela Teoria da Mudança Conceitual, e considerar a possibilidade da coexistência/convivência de conhecimentos alternativos e científicos. (CORDERO, 2002, p. 14)

Por meio deste estudo, descobriu-se que certos princípios específicos orientaram as relações entre as observações do céu e a teoria trabalhada em aula sobre este conteúdo, quando investigadas as várias versões de representações na construção do conceito de MDEC.

Recorrendo à literatura, em específico no ensino de ciências, encontramos Custódio e Pietrocola (2004), que estudaram os princípios como guias heurísticos ${ }^{4}$ genéricos na produção científica, e, segundo os autores: "Dentro de um processo de teorização, os princípios aparecem como guias genéricos, responsáveis pela organização das hipóteses e matematização do real físico, e ainda, cabe a eles de certa forma reger as verificações empíricas" (CUSTÓDIO; PIETROCOLA, 2004, p. 387).

Com essa capacidade de reger as verificações empíricas é que buscamos elaborar princípios para a mão dupla entre a observação do céu e modelos de representação no ensino de Astronomia, princípios estes que são: relação da altura do polo celeste com a latitude geográfica, obliquidade, continuidade do movimento, circularidade, tridimensionalidade e ciclicidade.

Tal abordagem de princípios como guias heurísticos somente veio a ser conhecida pelo pesquisador após o curso, em razão da necessidade de aprofundamento teórico da pesquisa realizada. Ao se estudar a possível evolução conceitual sobre o tema ensinado, descortinaram-se princípios norteadores do tema MDEC para o ensino de Astronomia. Esses princí-

\footnotetext{
${ }^{4}$ Heurístico: aquilo que serve de ideia diretriz numa pesquisa e se refere à descoberta. Um método é heurístico, o que leva o aluno a descobrir aquilo que se pretende que ele aprenda.
} 
pios foram verificados pela análise das respostas dos participantes e pelo estudo da evolução conceitual apresentada por eles durante o curso. Dessa forma, o curso teve uma abordagem própria e, posteriormente, foi feita a teorização a respeito. Contudo, os princípios mencionados aqui podem, oportunamente, ser usados no ensino deste conteúdo.

\section{Um curso de Astronomia para professores}

Foi realizado um curso de extensão, denominado "Introdução à Astronomia para Professores", promovido, em 2002, pelo Instituto Superior de Ciências Aplicadas (ISCA-Faculdades) em Limeira. O curso, com um total de 46 horas, foi oferecido a professores de ciências e geografia de $5^{a}$ a $8^{a}$ séries. Durante 14 semanas, aulas semanais abordaram os principais temas da Astronomia: História, Esfera Celeste, Astronomia de Posição, Sistema SolTerra-Lua, Sistema Solar, Estrelas, Galáxias e Cosmologia. Ocorreram duas práticas de observação do céu e foram utilizados modelos didáticos.

Nesta pesquisa foram enfocados os dados referentes a cinco professores que participaram do projeto completo, ou seja, além do curso, participaram, também, das reuniões que ocorreram posteriormente. São eles: B, J, R, SS e W, mencionados aqui por meio das iniciais de seus nomes - procedimento este autorizado por eles.

O estudo aqui relatado trabalha mais especificamente com a programação das aulas 5, 6 e 7, cujos conteúdos se referem à astronomia de posição, como: esfera celeste, coordenadas e movimentos da esfera celeste para diferentes latitudes.

Planejou-se seguir o programa já estabelecido previamente e sugerir ações extraclasse, particularmente, para observação do céu. Além disso, procurou-se dar voz ao professor e ouvir seus relatos a cada aula, tentando estabelecer uma ligação entre o que era relatado e o avanço da programação.

Tais relatos, que compreenderam narrações, textos, esquemas ou mesmo perguntas, mostraram ações individuais, envolvendo amigos e famílias dos participantes e, também, seus alunos, na sua prática pedagógica.

Tomando como ponto de partida a observação do céu ou a prática individual dos participantes, por estes relatadas, e usando os relatos como ideias prévias, foram trabalhados novos conceitos, pela sistematização de tais informações, avançando-se na programação.

A partir do movimento horário do Cruzeiro do Sul ao redor do polo celeste Sul, foram trabalhados os conceitos de esfera celeste e seus elementos, coordenadas celestes e movimento diário da esfera celeste para observadores em diversas latitudes.

\section{A observação do céu}

Um grande impulso para ações relacionadas à observação do céu, no curso aqui estudado, ocorreu a partir da observação, realizada no começo da noite, da Aula 5. Naquela oportunidade, foram utilizadas fotocópias das faces Sul e Norte e do planisfério do céu daquela data, no final do mês de abril (Figura 1), além de planisférios rotativos.

Eram visíveis as constelações do Cruzeiro do Sul, Órion e Leão, entre outras. Foi feita a identificação de constelações e estrelas mais brilhantes, em particular, Sírius, $\alpha$ e $\beta$ 


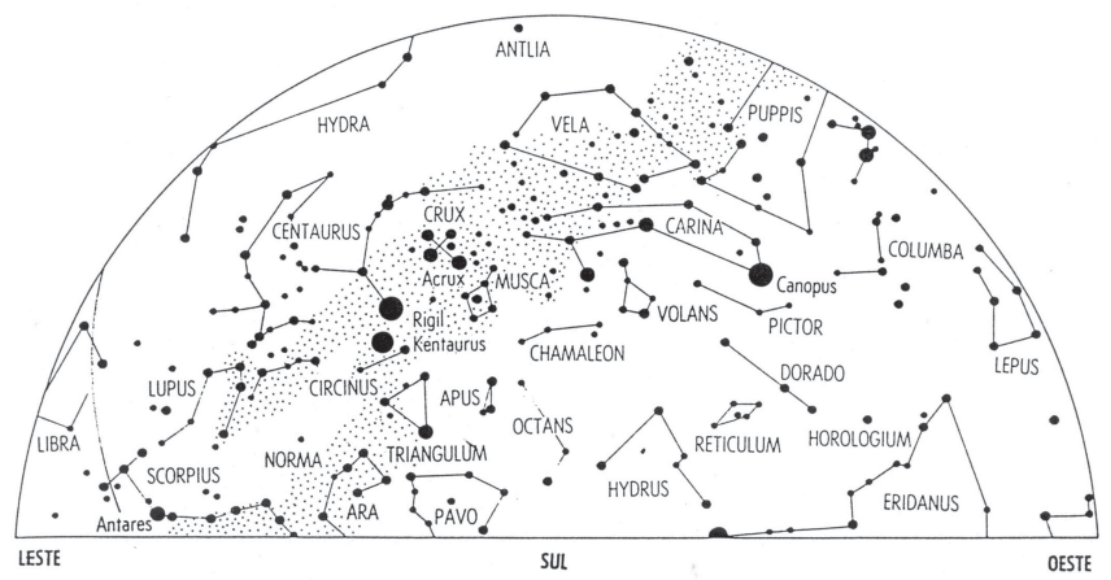

Figura 1. Mapa celeste da face Sul usado na observação da Aula 5.

Fonte: adaptado de Mourão (1997).

Centauri, Cástor e Pólux. Foi utilizada uma luneta de $60 \mathrm{~mm}$, com a qual se observaram a Lua e o planeta Júpiter. Ao final da atividade, sugeriu-se a possibilidade de práticas individuais de observação do céu para acompanhar os movimentos da esfera celeste e dos astros. Como sugestão inicial, solicitou-se que observassem o Cruzeiro do Sul e verificassem que tipo de movimento ele faz (para cima, para baixo, esquerda ou direita). Também se sugeriu que tentassem identificar, em suas cidades e condições, outras estrelas dos mapas fornecidos.

Dado o ponto de partida da observação ou da prática dos participantes, apresentado em seus relatos, no início da Aula 6, fez-se uso destes para seguir o eixo central da observação do céu.

Naquele momento do curso, havia, de um lado, a sugestão dada, na Aula 5, para que observassem o movimento da constelação do Cruzeiro Sul e, de outro lado, a necessidade de se cumprir o programa já estabelecido. Na ocasião, o programa planejado previamente considerava a abordagem de conteúdos sobre o MDEC. Dessa forma, foi conveniente iniciar a aula com os relatos dos participantes sobre o movimento do Cruzeiro do Sul. Conforme o planejamento inicial do curso, o conteúdo referente a esta aula seria relacionado ao MDEC; portanto, o professor-pesquisador optou por iniciar a aula partindo das observações do céu feitas pelos participantes antes dessa aula.

\section{A aula sobre o movimento diário da esfera celeste}

Logo no início da Aula 6, o professor-pesquisador solicitou os relatos dos participantes, que se apresentam a seguir.

W mostrou um caderno com desenho do céu e R fez relatos de observação do Cruzeiro do Sul e outras constelações com a família. Também SS fez relato, comentando que, em sua casa, não havia conseguido observar. Contudo, observou o céu na escola, pois a aula 
termina às 18h30. Apresentou relato de observação da constelação do Cruzeiro do Sul e mencionou seus alunos: "Como nós. É novidade, é um estímulo, achei o ponto fraco deles." (SS). Contou que possui um atlas celeste e que havia observado a Lua, com luneta, bem como as Três Marias. Esse relato de observações do Cruzeiro do Sul, feito por R, SS e W, deixa evidente o atendimento à solicitação da Aula 5. W, inclusive, acompanha seu relato com registros de desenhos feitos no seu caderno, já apresentados naquela aula.

Iniciar a aula com os depoimentos dos participantes, dando "voz" a eles, é partir de seus conhecimentos prévios, de suas experiências; é assumir uma perspectiva construtivista para tornar a aprendizagem significativa, como mencionado por Moreira (1997, p. 19, grifos do autor):

Aprendizagem significativa é o processo através do qual uma nova informação (um novo conhecimento) se relaciona de maneira não arbitrária e substantiva (não-literal) à estrutura cognitiva do aprendiz. É no curso da aprendizagem significativa que o significado lógico do material de aprendizagem se transforma em significado psicológico para o sujeito.

Dessa forma, é com a prática da observação da natureza que os participantes interagem com o meio físico, conforme valorizado por Compiani e Carneiro (1993). E, particularmente, dedicam-se à observação do céu, como aponta Lanciano (1989).

Por isso, mesmo após a sugestão inicial de que os participantes observassem o céu, estimulou-se, durante todo o curso, que continuassem a observar. Conforme será apresentado adiante, em muitos momentos, os participantes fizeram tais observações, procurando confrontar o conhecimento que já possuíam com novas experiências relacionadas a vários objetos e fenômenos celestes.

Com esses depoimentos dos participantes, ainda na Aula 6, o professor lembrou-se da posição do Cruzeiro na noite de observação da Aula 5 e sistematizou a questão na lousa. Com as informações, trazidas pelos alunos, de que o Cruzeiro descreve um movimento horário no céu, algumas posições foram desenhadas na lousa. Discutiu-se que, se uma volta completa é dada em um dia, conclui-se que a constelação percorre $90^{\circ} \mathrm{em}$, aproximadamente, seis horas.

Procurou-se relacionar esses relatos trazidos pelos participantes ao conteúdo referente ao MDEC, por meio dos conceitos descritos a seguir. Esses dados foram anotados na lousa.

Conforme sua posição na Terra, em especial sua latitude, uma pessoa pode observar um determinado movimento da esfera celeste, que é diferente para observadores posicionados em diferentes latitudes na Terra. Como mostra a Figura 2, podem-se verificar os três tipos principais de movimentos diários dos astros na esfera celeste, respectivamente, para observadores em três diferentes latitudes na Terra.

Para um observador no equador terrestre, os astros nascem no horizonte Leste, descrevem círculos perpendiculares ao horizonte e se põem no horizonte Oeste. Os polos Sul e Norte celestes coincidem com os pontos cardeais Sul e Norte, e estão no horizonte do local.

Já para um observador no polo terrestre, os astros não nascem e nem se põem, apenas descrevem movimentos circulares ao redor do polo celeste, que coincide com o zênite nesse local. 


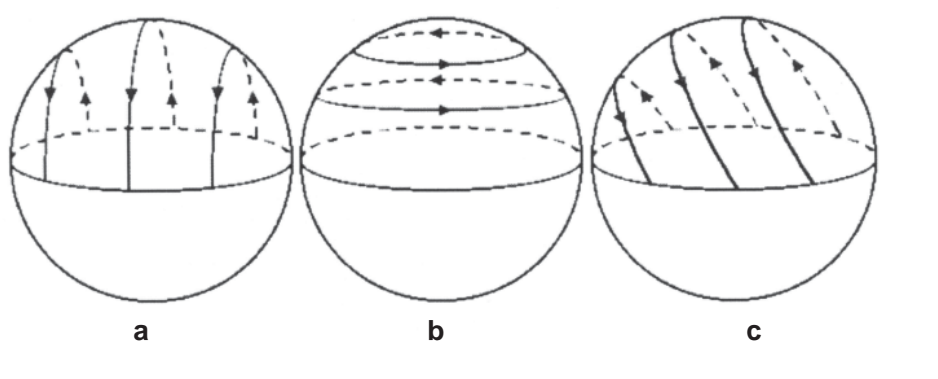

Figura 2. Movimento diário da esfera celeste para várias latitudes.

Fonte: Bretones (2006).

Finalmente, para um observador entre o polo e o equador, os astros são observados descrevendo movimentos circulares oblíquos ou inclinados com relação ao horizonte. Para este observador, alguns astros estariam sempre acima do horizonte, nas proximidades do polo celeste, e outros sempre abaixo do horizonte, nunca visíveis em sua latitude. Particularmente para um observador no hemisfério Sul, o movimento dos astros ao redor do polo pode ser percebido localizando-se a constelação do Cruzeiro do Sul. Conforme a Figura 3, tomando-se como ponto de partida certa noite e um determinado horário, o Cruzeiro pode estar na posição 1. Com o avanço da noite ou com o passar das horas, pode-se observar o Cruzeiro deslocar-se para a posição 2, movendo-se no sentido horário. Mais tarde, ocorre mudança de posição da constelação para a posição 3 .

Verifica-se, então, que o conhecimento do MDEC permite determinar, entre outras coisas, a latitude de um observador. Para tanto, é necessário que tal observador acompanhe o movimento de um ponto, que pode ser a Lua, o Sol, um determinado planeta, uma estrela ou, melhor ainda, um grupo de pontos - o que equivale a dizer: uma constelação.

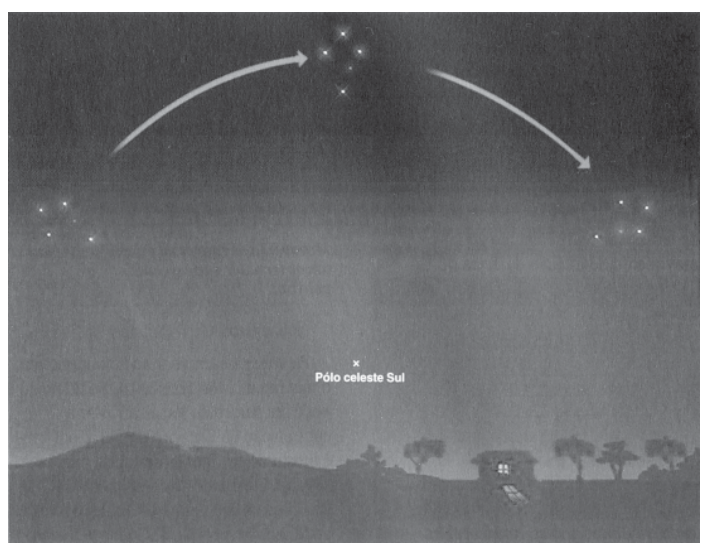

Figura 3. Movimento da constelação do Cruzeiro do Sul ao redor do polo celeste Sul (sentido horário).

Fonte: Bretones (1995). 
Identificar o sentido do movimento de uma constelação, logo após o seu nascer no horizonte Leste, requer apenas o uso de uma seta, que representa um conhecimento importante e pode ser usado no relacionamento com outros conteúdos: rotação e translação da Terra, eixo do mundo, polos Norte e Sul da Terra, equador terrestre, coordenadas terrestres - latitude e longitude, esfera celeste e seus elementos.

Além disso, na Aula 7, tais conteúdos referentes ao MDEC para diferentes latitudes foram relembrados em aula expositiva, em que também houve a apresentação de modelos do globo (da esfera) celeste: modelo comercial com estrelas pintadas, balão de vidro e esfera de isopor (Figuras 4a, 4b e 4c, respectivamente). O modelo representado em 4b refere-se, particularmente, ao proposto por Caniato (1990).

Contudo, tais modelos apenas foram demonstrados pelo professor, não tendo chegado a ocorrer a construção e a manipulação mais demorada pelos participantes.
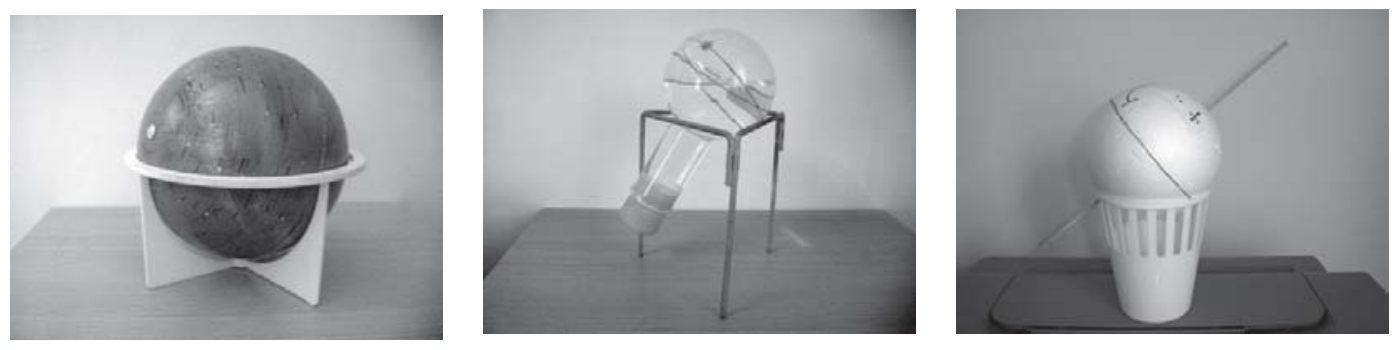

Figura 4. Modelos de globos da esfera celeste.

Fonte: Fotos de Paulo S. Bretones.

\section{Análise das avaliações}

Tendo em vista verificar a evolução dos conceitos sobre o MDEC, apresentada pelos participantes, procurou-se analisar as respostas dadas nas avaliações que fizeram.

Com a análise de tais respostas, buscaram-se, nas diferentes avaliações realizadas ao longo dos vários momentos do curso, evidências do efeito propiciado pela teoria trabalhada em aula, decorrente das práticas de observação relatadas pelos participantes e das compreensões e dos diálogos instaurados com o professor.

Pedir para um participante de curso introdutório de Astronomia reconhecer ou identificar uma constelação, perguntando-lhe o nome desta, seria exigir muito, logo no início do curso. Mais do que isso, o conhecimento e a memorização da figura de uma constelação são algo que deve ocorrer com o aumento da familiaridade do participante com o céu e ao longo do tempo, como decorrência de repetidas observações incorporadas em sua experiência. Isso poderia ser acompanhado, no decorrer do aprendizado do participante, pelo conhecimento do desenho de uma constelação e por sua identificação a partir desse desenho. Contudo, julgouse mais importante, simplesmente, identificar uma ou mais constelações, abordar o entendimento de que tipo de movimento elas fazem na esfera celeste, para um determinado observador, em especial o próprio participante, que está localizado em uma latitude intermediária no hemisfério Sul. 
O conteúdo referente ao movimento diurno da esfera celeste ou de uma constelação foi avaliado, inicialmente, por meio da seguinte questão do Questionário de Conteúdos Prévios (QP) aplicado no início da Aula 1 (Figura 5).

Após a abordagem dos conteúdos de esfera celeste em aula, foi aplicada uma avaliação escrita $\left(\mathrm{P}_{2}\right)$, no início da Aula 9, na qual foram feitas as seguintes questões (Figura 6).

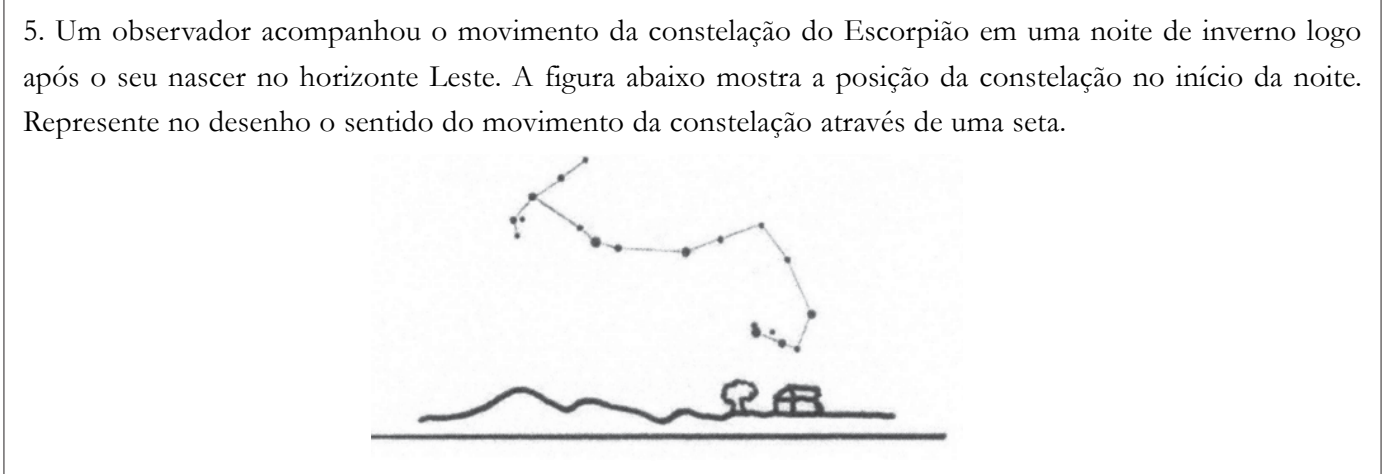

Figura 5. Questão no 5 do questionário de conteúdos prévios (QP).

Fonte: Bretones (2006)

4. Um observador acompanhou o movimento da constelação do Órion em uma noite de verão logo após o seu nascer no horizonte Leste. A figura abaixo mostra a posição da constelação no início da noite. Represente no desenho o sentido do movimento da constelação através de uma seta.

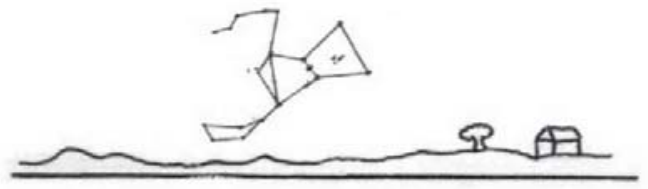

5) Um observador resolveu acompanhar o movimento do Cruzeiro do Sul durante uma noite de inverno. Sabese que esta constelação pode funcionar como [faz o movimento dos] os ponteiros de um relógio devido ao seu movimento. A figura abaixo mostra a constelação na posição (1) às 21 horas. a) Represente, no desenho, o sentido do movimento da constelação através de uma seta; b) Indique a que horas o Cruzeiro será visto na posição (2); c) Indique, no desenho, a posição esperada para o Cruzeiro às 3 horas da madrugada.

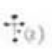

R A f

Figura 6. Questões n. 4 e n. 5 da Prova $P_{2}$.

Fonte: Bretones (2006) 
Bretones, P. S.; Compiani, M.

$\mathrm{Na}$ última aula (A14), o mesmo conteúdo foi avaliado, entre os participantes, por meio da seguinte questão do Questionário Final e Conteúdos (QF):

4) Mostre, usando esquemas, a trajetória de uma constelação típica de verão no hemisfério sul, logo após o seu nascer no horizonte Leste.

As respostas dadas pelos participantes são apresentadas na Figura 7, simplificadas apenas pelo uso de setas e direções no Quadro 1, e a discussão é feita a seguir.

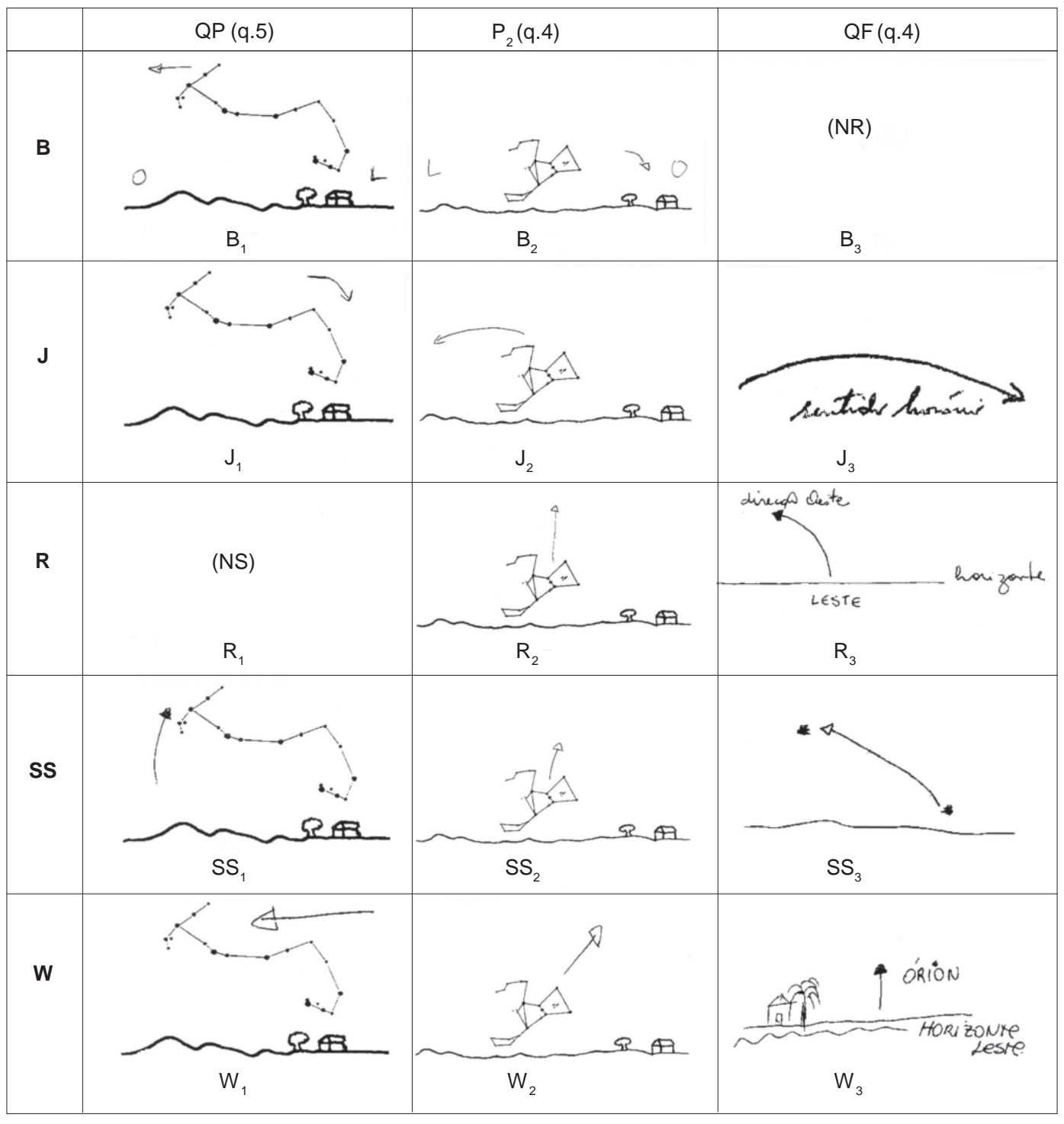

Figura 7. Respostas dos participantes às perguntas (q.5 do QP, q.4 da $P_{2}$ e q.4 do QF) sobre o movimento da esfera celeste, com figuras de constelações e setas.

Fonte: Bretones (2006)

Ciência \&̊ Educacão, v. 17, n. 3, p. 735-755, 2011 
As questões permitem fazer um estudo sobre a evolução conceitual do movimento da esfera celeste pelos participantes.

Para as questões relacionadas aos movimentos de constelações logo após o nascer no horizonte Leste, não foi mencionado, mas considerou-se que se relacionavam a observadores próximos ao Trópico de Capricórnio, na latitude dos participantes. Contudo, as posições apresentadas para as constelações do Escorpião e do Órion correspondiam ao aspecto que elas têm, ao nascer, nas referidas latitudes.

Quadro 1. Respostas dos participantes às perguntas (q.5 do QP, q.4 da $P_{2}$ e q.4 do QF) sobre o movimento da esfera celeste, simplificadas apenas com setas.

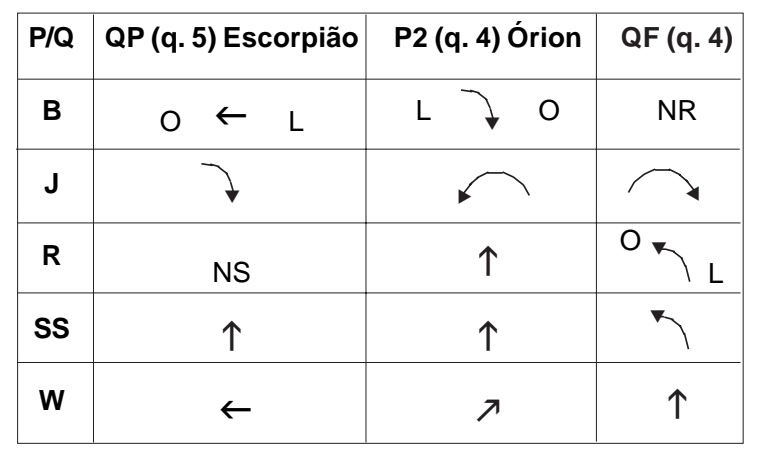

Fonte: Bretones (2006).

Mesmo assim, levando-se em conta outras possíveis respostas, referentes às outras latitudes extremas, é importante considerar:

a) Para um observador no Equador, o correto seria uma seta para cima, perpendicular ao horizonte.

b) Para um observador no polo Sul, o Escorpião estaria o tempo todo acima do horizonte e descreveria um movimento paralelo ao horizonte. Para esse observador, apenas metade do Órion estaria acima do horizonte, e esta constelação também descreveria um movimento paralelo ao horizonte.

c) Para um observador no polo Norte, o Escorpião estaria o tempo todo abaixo do horizonte e não seria visível, e apenas metade do Órion estaria acima do horizonte e descreveria um movimento paralelo ao horizonte.

Há, ainda, outra variável nas possíveis respostas dadas a estas questões. Foi solicitada a resposta quanto ao "logo após" o nascer da constelação no horizonte Leste, mas não foi pedido que apresentassem toda a trajetória que a constelação faria ao longo de uma noite. Dessa forma, referente às questões formuladas para uma constelação "logo após o seu nascer no horizonte Leste", a resposta mais correta para nossas latitudes seria uma seta para cima inclinada para a esquerda com a seguinte orientação: $\nwarrow$. 
Mas ainda poderia ser considerada correta a resposta de uma seta para cima, para o caso do observador no Equador.

Dentre as respostas referentes à questão 5 , no início do curso, para a primeira avaliação (Qp), apenas um participante mostrou um arco para cima [个] (SS). Dois outros mostraram setas horizontais para a esquerda $[\leftarrow](\mathrm{W})$, mas um deles acrescentou Leste para Oeste: $[\mathrm{O} \leftarrow \mathrm{L}](\mathrm{B})$. Outro representou um arco para baixo $(\neg)(\mathrm{J})$, e outro, ainda, respondeu "Não sei" (R).

É possível notar, dessa forma, que a grande maioria da amostra iniciou o curso sem conhecer o movimento diurno da esfera celeste para uma constelação que acabara de nascer no horizonte Leste. Conforme mencionado, a resposta mais correta seria uma seta para cima inclinada para a esquerda. Ocorre que a seta simplesmente para cima (SS) já representa certo conhecimento. A resposta de B, mostrando uma seta de Leste para Oeste, revela uma concepção comum dos não iniciados em Astronomia: todos os astros nascem a Leste e se põem a Oeste. Quanto à resposta de J, de um arco para baixo, está incorreta, pois, segundo a questão formulada, a constelação acaba de nascer.

$\mathbf{N a}$ avaliação de conteúdos de Astronomia de Posição $\left(\mathbf{P}_{2}\right)$, ocorrem respostas à questão 4 que mostram arcos no sentido anti-horário (J), no sentido horário e com referências Leste e Oeste (B), setas para cima (R, SS) e para cima inclinadas à direita (W).

Os arcos e as setas para cima, apresentados nas respostas verificadas a partir da $\mathrm{P}_{2}$, mostram o efeito da teoria trabalhada no curso e da prática de observação do céu pelos participantes. Numa análise inicial, verificam-se setas apontadas para cima apenas nas respostas de R, SS e W. Tal mudança pode relacionar-se à observação do céu. Diferentemente de B e J, eles representam, na questão que aparece a figura da constelação de Órion, setas para cima, mesmo sendo inclinadas para a direita (W). As setas representam que a constelação deve distanciar-se do horizonte e ganhar altura progressivamente. Isso já não ocorre com as respostas de B e J, que apresentam curvas para baixo (B) e para a esquerda, no sentido anti-horário (J).

No que se refere à questão 5 , todos os participantes acertaram o sentido do movimento aparente da constelação no céu, ou seja, o sentido horário.

Estas foram as respostas referentes à questão 4, no final do curso, para a última avaliação (QF): seta para cima (W), arco para cima à esquerda (SS) e com referências Leste para Oeste (R), arco no sentido horário (J), e o participante B não respondeu. Isso mostra que, sem o apoio da figura da constelação, deve prevalecer, na resposta, o conhecimento que o aluno traz da base teórica ou da prática de observação do céu.

A seta para cima (W), simplesmente, mostra o pensamento de quem o tem mais ligado ao hábito da observação, dada a própria dificuldade, na prática, de verificar a inclinação ou a obliquidade no movimento da constelação, o que resultaria numa seta inclinada para cima e à esquerda.

Os arcos para cima à esquerda (R e SS) mostram uma contribuição da teoria, dada a tentativa de representação da esfericidade ou circularidade do movimento da esfera celeste e um distanciamento progressivo da constelação com relação ao horizonte, fruto da experiência observacional do participante.

Já o arco no sentido horário (J) mostra apenas uma referência à teoria, trabalhada na aula, sobre o movimento do Cruzeiro, por estar próximo ao polo, o que claramente não se aplica à constelação indicada na pergunta formulada. 
Evolução conceitual de professores ...

Analisando-se, ainda, as respostas, procurou-se fazer um estudo da evolução conceitual para o movimento de uma constelação, após nascer no horizonte Leste, para um observador em latitude intermediária. Para tanto, iniciou-se pela elaboração do Quadro 2, que mostra a sequência de respostas de cada participante e uma distribuição de evolução conceitual:

Quadro 2. Sequência de evolução conceitual verificada nas respostas por participante (P), para o movimento da constelação, após nascer no horizonte. Os símbolos representam os conceitos apresentados em cada avaliação:

- - QP;

$\Delta-\mathrm{P}_{2} ; \quad \mathbf{Q}-\mathrm{QF}$.

\begin{tabular}{|c|c|c|c|c|c|c|}
\hline Mov. Const. $P$ & B & $\mathbf{J}$ & $\mathbf{R}$ & SS & W & \multirow{4}{*}{$\begin{array}{c}\text { [Prática } \\
+ \\
\text { Teoria] }\end{array}$} \\
\hline 12) $\pi$ & & & & & & \\
\hline 11) $\mathrm{O} \overbrace{\mathrm{L}}$ & & & 0 & & & \\
\hline 10) & & & & 0 & & \\
\hline 9) $\quad \uparrow$ & & & $\boldsymbol{\Delta}$ & $\bullet \mathbf{A}$ & & [Prática] \\
\hline 8) & & & & & $\Delta$ & \\
\hline 7) $\quad$ & & - & & & & [Teoria] \\
\hline 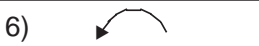 & & $\Delta$ & & & & \\
\hline 5) $\mathrm{L} D$ & $\Delta$ & & & & & \\
\hline 4) & & - & & & & \\
\hline 3) $\mathrm{O} \leftarrow \mathrm{L}$ & $\bullet$ & & & & & \\
\hline 2) $\quad \leftarrow$ & & & & & & [Iniciais] \\
\hline 1) $\quad \mathrm{NS}$ & & & $\bullet$ & & & \\
\hline
\end{tabular}

Fonte: Bretones (2006)

Percebem-se graus diferentes na hierarquia da formação de conceitos sobre o movimento da constelação. Os conceitos verificados são explicados a seguir, conforme o número atribuído no Quadro 2, referente à interpretação dada às respostas atribuídas à questão.

1) Resposta "não sei" (NS).

2) Seta para a esquerda.

3) Seta para a esquerda, acrescida da referência ao sentido do movimento de Leste para Oeste.

4) Seta ou arco apontado para baixo, o que não pode ocorrer com a constelação que nasce no horizonte Leste. 
5) Seta ou arco apontado para baixo, acrescido da referência ao sentido do movimento de Leste para Oeste.

6) Arco no sentido anti-horário, indicando uma tentativa de representar o movimento da esfera celeste no desenho.

7) Arco no sentido horário, indicando uma tentativa de representar o movimento da esfera celeste. Provavelmente, aqui, ocorre uma ligação com o movimento horário do Cruzeiro do Sul, trabalhado no curso, em lousa, e apresentado nos relatos dos participantes.

8) Seta para cima e inclinada para a direita. É o primeiro desenho da sequência que representa o movimento para cima.

9) Seta para cima, o que representa uma boa aproximação com a realidade, concebendo que a constelação parte do horizonte e ganha, cada vez mais, altura com o passar do tempo.

10) Seta para cima em arco, inclinada para a esquerda, indicando uma tentativa de mostrar a representação da esfera celeste no desenho.

11) Seta para cima em arco, inclinada para a esquerda, acrescida da referência ao sentido do movimento de Leste para Oeste, tornando a representação mais clara.

12) A melhor representação seria uma seta para cima e inclinada para a esquerda. Isso não foi verificado em qualquer resposta.

O Quadro 2 foi preparado para apresentar uma sequência de evolução para cada um dos participantes. Assim, numa análise mais geral, são notados dois blocos de participantes. $\mathrm{O}$ primeiro formado por B e J, e o segundo formado por R, SS e W.

Estes últimos mostram evolução mais destacada do que B e J, provavelmente por terem observado o céu: não apenas observaram o Cruzeiro do Sul, mas também relataram observações do Escorpião e do Órion. Reportaram ter observado o movimento horário da constelação do Cruzeiro do Sul, e isso foi sistematizado e mostrado em lousa com mais explicações, como a questão - detalhada em aula - de que o Cruzeiro percorre aproximadamente $90^{\circ}$ a cada seis horas. Como resposta à questão 5 , feita na $\mathrm{P}_{2}$, os três acertaram o sentido anti-horário, por meio de uma seta.

A mudança verificada nos participantes que passaram a apresentar curvas (B e J) estaria relacionada à aula sobre o movimento do Cruzeiro e ao uso de figuras da esfera celeste.

Porém B não apresentou seta com movimento horário em $\mathrm{P}_{2}$, mostrou corretamente os arcos em QF (quando respondeu à questão 3, referente ao movimento do Sol na esfera celeste), e não respondeu quanto ao movimento da constelação em QF. Isso representa reprodução dos esquemas mostrados em aula e até a assimilação da ideia do movimento horário da constelação do Cruzeiro do Sul, o que teria ficado meramente no âmbito do enunciado da ideia. Em outras palavras, foi assimilada pelo participante apenas a ideia de que as constelações têm movimentos horários, e não o ponto de vista de quem observa uma constelação logo após seu nascer no horizonte Leste. Há ainda uma falta de ligação disso com o movimento observado no céu para a constelação, o que leva à ausência de resposta em uma questão que não apresenta o apoio da imagem da constelação. Uma proposta de explicação está na ausência de relatos desse tipo de observações do céu por este participante: não apresentou relato de observação e apenas evoluiu na $\mathrm{P}_{2}$, para a representação de um arco no sentido horário, mas mantendo a referência ao sentido do movimento de Leste para Oeste, o que também pode ser considerado um avanço conceitual. 
Quanto a J, não apresentou relato, provavelmente por não ter observado o movimento do Cruzeiro nem de outras constelações próximas ou no equador celeste, como é o caso do Escorpião e do Órion. Apenas evoluiu, na $\mathrm{P}_{2}$ para a representação de um arco para a esquerda e, no QF, para a representação de um arco no sentido horário.

Tanto no caso das respostas de B quanto nas de J pode-se verificar o papel da teoria sem a prática. Para o caso da observação do céu, fica evidente a necessidade de se trabalhar a prática, o que pode ser feito não apenas com mais observações do céu, mas também com o uso de modelos tridimensionais ou até, quando disponível, com o auxílio de um planetário.

Em todos os casos, porém, verifica-se a falta de acompanhamento, pelo professor-pesquisador, dos resultados das avaliações, logo após terem sido feitas pelos participantes. Tendo em vista a finalidade de elaborar avaliações para obtenção de dados, o professor-pesquisador não teve o cuidado de verificar as respostas dadas pelos participantes na época do curso, trabalhar a correção das avaliações com eles e, com isso, tomar decisões quanto a outras atividades e ao avanço do conteúdo.

\section{Princípios na observação da esfera celeste}

Procurando simplificar ainda mais, fez-se um agrupamento das respostas ${ }^{5}$ por meio de caixas, à direita do Quadro 2, e elaborou-se um esquema que mostra a evolução conceitual verificada neste estudo (Figura 8).

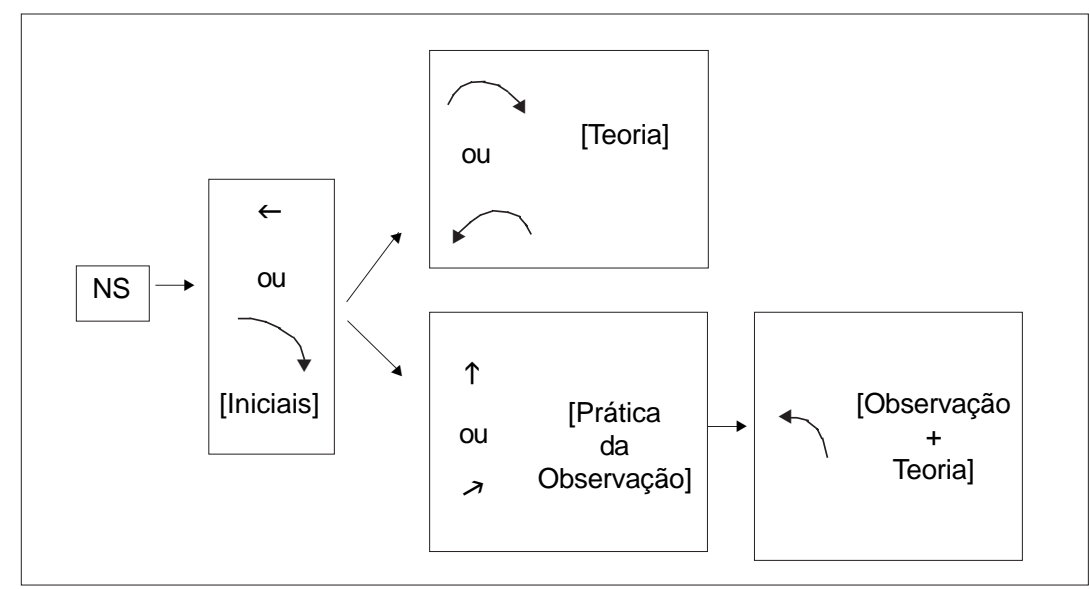

Figura 8. Sequência de evolução conceitual do movimento da constelação, após nascer no horizonte leste, mostrando desde respostas iniciais, passando por respostas que mostram o efeito da prática da observação ou da teoria trabalhada em aula e respostas que mostram a relação da prática com a teoria.

Fonte: Bretones (2006).

\footnotetext{
${ }^{5}$ Os agrupamentos de respostas mencionados pelas caixas no Quadro 2 correspondem às indicações entre colchetes, na Figura 8, e serão indicados, também, entre colchetes no relato a seguir.
} 
Percebe-se que, partindo das respostas iniciais [Iniciais], verificam-se dois caminhos percorridos pelos dois grupos de participantes deste estudo. Para o caso de B e J, a evolução segue o sentido da teoria, quando apresentam arcos referentes a ângulos maiores [Teoria]. Já R, SS e W apresentam uma evolução, inicialmente, pela prática da observação, quando apresentam setas para cima [Prática], e, posteriormente, no sentido da observação, em conjunto com a teoria, quando apresentam arcos, mas voltados para cima e para a esquerda [Prática + Teoria].

A representação das observações do céu em conjunto com a teoria trabalhada em aula sobre o MDEC, com a representação de arcos, mais uma vez encontra consonância na abordagem das excursões e nas observações de campo na Geologia, conforme assinalam Compiani e Carneiro (1993, p. 92): "É preciso formalizar as informações tomadas no campo e resolver adequadamente sua representação visual, para permitir a comunicação com outras pessoas".

Dessa forma, percebe-se que os participantes que observaram o céu tiveram mais condições de fazer a relação entre o que observaram e a abordagem das representações com desenhos no papel. Contudo, a representação não foi plenamente desenvolvida por falta de atividades, por falta de tempo, dada a preocupação do professor-pesquisador em cumprir o programa preestabelecido, o que impediu que exercitassem tal relação entre teoria e prática durante o curso.

A ausência de articulação entre a observação direta do céu e o uso de modelos e representações para a formação de conceitos leva a dificuldades do aprendiz, no que diz respeito à representação da esfera em três dimensões, como afirma Lanciano (1989, p. 176):

A distância entre o modelo e sua representação, por um lado, e a realidade modelizada por outro, não se recorre nos dois sentidos: da realidade ao modelo e do modelo à realidade. E esta desconexão pode durar muito.

Um problema importante, tanto no ensino das matemáticas, como no ensino da astronomia, é o que está ligado à visão espacial, à capacidade mental de ver em três dimensões.

As representações dos livros, as imagens de vídeo, os quadro negros, etc. esmagam o espaço e não lhe dão dinamicidade. (BRACESSI; BALADA, 1980; BRACCESSI, 1983 apud LANCIANO, 1989, p. 176, grifos da autora, tradução nossa)

A mesma autora (LANCIANO, 1989), quando defende que a observação direta do céu, de seus objetos e de seus fenômenos, tanto de noite como de dia, é fundamental e insubstituível, propõe que:

Se se utiliza o observatório privilegiado da Astronomia, que é o céu, a verdadeira natureza e não suas imagens, muitas coisas se nos apresentam mais claras e menos complexas.

Os elementos da tridimensionalidade do espaço, a esfericidade dos objetos, a circularidade dos movimentos e seu caráter contínuo, a verdadeira duraşão dos fenômenos, quando em parte ou em sua totalidade são observados 
diretamente, podem ser uma base de conhecimento muito mais sólida, estável e intuitiva que as figuras, os discursos, os nomes e inclusive os modelos.

Por outro lado, no caso particular da Astronomia, o estupor, a capacidade de assombro de cada um ante a beleza e a grandiosidade do céu podem constituir a base para desejar conhecer, saber, estudar ou para gozar ao máximo. A profundidade do céu, dentro do espaço vazio, que nos circunda e em que estamos imersos se evoca melhor com um céu estrelado, que com uma lição na lousa. Evocar, quer dizer sugerir à mente, ajudar a compreender, a penetrar. (LANCIANO, 1989, p. 180181, grifos da autora, tradução nossa)

Neste ponto, pode-se fazer uso de princípios para o ensino de tais conteúdos e, também, para facilitar o estudo aqui desenvolvido.

Para Custódio e Pietrocola (2004, p. 385), "nas ciências empíricas, um princípio pode ser tomado como um ponto de partida de uma dedução, mas formulado como interpretação, generalização e abstração de um saber anterior".

Tomam-se, dessa forma, os princípios como generalizações de regularidades ou propriedades constatadas em experimentos, conforme mencionado por Custódio e Pietrocola (2004, p. 385):

Para Einstein (1998, p. 142), os princípios nas ciências empíricas servem de base para a formulação de todas as hipóteses, e é a partir deles que se pode deduzir conseqüências. Assim, o trabalho do cientista consiste necessariamente em buscar uma certa regularidade, uma propriedade a ser generalizada, uma lei que determine a evolução do sistema considerado e que principalmente sirva de princípio geral da natureza. De posse de tais princípios, pode-se procurar, via observação, nos fatos experimentais, características gerais e exatas, a serem explicitadas nitidamente. Quando esta formulação obtiver êxito, começa então o desenvolvimento das conseqüências, que muitas vezes revelam relações insuspeitadas que transcendem o campo dos fatos de onde foram tirados os princípios.

Tais princípios observados em experimentos podem ser verificados nas observações do céu, no caso da Astronomia.

Segundo Paty (2003), um princípio serve de guia a restrições de leis possíveis, uma função teórica que não é suficiente para a construção de uma teoria, mas é capaz de limitar consideravelmente as possíveis arbitrariedades dentro de um sistema teórico. Ainda conforme Custódio e Pietrocola (2004, p. 390), isso quer dizer que "dentre as várias hipóteses a serem lançadas no processo de construção teórica, temos condições de restringir e simplificar uma série de formulações para leis de uma certa classe de fenômenos".

O objetivo da questão proposta nas avaliações era analisar o sentido e a direção por meio de uma seta. Tendo em conta que isso mostra um movimento, deve-se verificar a repre- 
sentação para dois pontos relativamente próximos ou dois pontos mais distantes, o que remete à questão do tempo decorrido.

Dessa forma, para representações em pequena escala de tempo, a seta mais correta é: $(\pi)$, mas, com o passar das horas, a constelação faria uma trajetória do tipo: 7 e, com mais tempo ainda, do tipo: $\square$.

Considerando-se o que se pode chamar de princípio da relação da altura do polo celeste com a latitude geográfica, teremos três situações, das quais apenas duas são possíveis, conforme o enunciado do problema, para uma constelação que acaba de nascer: $\mathbf{a}, \mathbf{b}$ e c. (Figura 2). A estas possibilidades chamamos de esfera reta, esfera paralela e esfera oblíqua, respectivamente.

Assim, como restrição a este princípio, são excluídos $\mathrm{W}_{1}$ e $\mathrm{B}_{1}$, pois mostram setas do tipo $(\leftarrow)$, o que só se verifica para o caso de constelações vistas por observadores no polo.

Neste caso, tais princípios são indutivos, e não dedutivos. Iniciando-se pela observação do céu, posteriormente, os modelos são utilizados, como na Figura 2, em aula expositiva ou demonstração de modelos da esfera celeste para a formação de conceitos.

O princípio da relação da altura do polo com a latitude geográfica foi verificado pelas representações de setas para cima. Neste caso, foram verificadas setas do tipo: $\uparrow$ ou $\nearrow$.

Ocorre que, no caso aqui estudado, com os dados disponíveis, verificou-se que as setas para cima mostram relação com a observação do céu, sob o ponto de vista de que uma determinada constelação, após nascer no horizonte leste, passa a ficar cada vez mais alta no céu, indo para cima. Assim, setas ascendentes representam a relação da altura do polo com a latitude, excluindo a possibilidade de setas paralelas ao horizonte. Aqui seria uma indicação de que não houve observação mais atenta, para se verificar a inclinação da trajetória da constelação. Apenas ocorreu a verificação de que os astros sobem na esfera celeste, após nascerem no leste. Por isso, foram excluídas as setas para a esquerda, por se tratar de constelação que acaba de nascer; e, também, seriam aceitas as representações do tipo $(\uparrow)$, pois mostrariam apenas o componente de ascensão/para cima, no sentido do movimento que se pede.

Aqui, o princípio da obliquidade apenas seria verificado para o caso de latitude intermediária (Figura 2c). Tal princípio seria verificado pelo uso de setas inclinadas e, mais corretamente, para a esquerda - o que não foi verificado pelos dados obtidos. Contudo, tal princípio mostraria um passo a mais com relação ao anterior. Além de ser voltada para cima, a seta seria inclinada e, no caso de observadores no hemisfério Sul, para a esquerda: $\nwarrow$.

Outro princípio verificado é o da continuidade do movimento da esfera celeste. Por causa dele, também são excluídas as representações do tipo $\mathrm{B}_{2} \mathrm{e} \mathrm{J}_{1}$, que mostram setas do tipo $(\neg$ ). Tais representações mostrariam casos de movimento horizontal seguido de movimento para baixo, coisa que não ocorre no movimento diário da esfera celeste. Neste caso, as setas indicaram descontinuidade, pois o padrão inicial foi alterado.

Este princípio é revelado por setas em forma de arcos do tipo: $\$ apresentadas em $\mathrm{R}_{3}$ e $\mathrm{SS}_{3}$. Para esta trajetória ser verificada pela observação, seria necessário um tempo de observação de algumas horas, após o nascer da constelação no horizonte Leste, coisa que não foi relatada pelos participantes. Também desenhos, como na Figura 2, ou mesmo o uso de modelos de esfera celeste, quando colocados para girar em pequenos ou grandes arcos, mostram o que ocorre com a esfera celeste com o passar das horas. 
$\mathrm{Na}$ sequência, o princípio da circularidade do movimento da esfera celeste pode ser constatado nas representações do tipo $(\neg) \mathrm{e}(\curvearrowleft)$, apresentadas em $\mathrm{J}_{2}$ e J ${ }_{3}$. Tal movimento para determinada constelação pode ser aceito, levando-se em conta um arco maior referente a um tempo decorrido de maior duração. Isso ocorreria pela trajetória de determinada constelação em algumas horas, passando pelo ponto mais alto da esfera celeste para o seu caso, o que equivale a dizer que passaria pelo meridiano celeste local. Ocorre que o participante $\mathrm{J}$ não relatou práticas observacionais que mencionassem tal movimento para certa constelação, mesmo porque ele menciona sentido horário, e isso está diretamente ligado e, portanto, mais possivelmente determinado pela aula referente ao movimento da constelação do Cruzeiro do Sul. Tal movimento é horário, ao redor do polo, e sua representação similar foi mostrada em aula. Este princípio também é apresentado por meio de desenhos ou, mesmo, pelo uso de modelos de esfera celeste, quando colocados para girar em grandes arcos, chegando a dar voltas completas - uma característica positiva do modelo, pois se pode fazer isso de maneira acelerada.

Finalmente, apresenta-se o princípio da tridimensionalidade, porque há um esforço de representação, nos casos de $\mathrm{R}_{3}$ e $\mathrm{SS}_{3}$, de um arco para cima e à esquerda, o que confere um caráter de ascensão e, também, de curva, e seria uma parte de um arco representado na Figura 2c.

A observação do céu por algumas horas ou em determinados momentos, com intervalos de horas, juntamente com os modelos de esfera celeste, pode ser muito útil na formação do conceito de que tal movimento é espacial, mas requer um esforço para ser representado no plano por meio de arcos. Usando o exemplo aqui estudado para a observação do movimento de uma constelação nas proximidades do polo celeste Sul, é fácil constatar a existência de arcos ao longo das horas. Contudo, para constelações mais afastadas do polo, digamos, nas proximidades do equador celeste ou da eclíptica, a observação - se possível, acompanhada do uso de modelos - permite trabalhar o princípio da tridimensionalidade. Neste caso, a observação acompanhada do uso de modelos é muito importante, dadas as limitações dos desenhos feitos no plano - para o aprendiz.

\section{Considerações finais}

Vários aspectos positivos e úteis para o ensino de conteúdos relacionados à observação do céu podem ser verificados, se estes forem associadas ao uso de princípios e suas representações. Os princípios da observação e da representação do céu aqui abordados podem ser usados para se extrair o máximo de cada prática de observação associada à representação e ao desenvolvimento da teoria em aula. Cada um dos princípios pode ser usado para o ensino de um aspecto específico, e a sequência, o conjunto, pode ser útil para a elaboração do conceito de movimento diário da esfera celeste.

Com atividades mais frequentes de observação e com o uso de modelos, seria muito importante a prática de desenhos para representar o MDEC, para representar no papel, portanto em duas dimensões, e no plano, movimentos que ocorrem em três dimensões.

Contudo, há necessidade de se observarem tais resultados em um grupo maior, com a utilização de uma metodologia mais construtivista do que tradicional. $\mathrm{O}$ estudo aqui apresentado foi feito com um grupo de apenas cinco professores. Um estudo posterior poderia ser 
Bretones, P. S.; Compiani, M.

feito com um grupo com maior número de participantes, a fim de se testarem e aprofundarem os resultados aqui verificados.

Isso seria possível não apenas com mais observações diretas do céu e por períodos prolongados - o que contribuiria para o uso dos princípios de direção, obliquidade e circularidade dos movimentos, bem como o caráter contínuo em diversas oportunidades - mas, também, procurando-se desenvolver a representação espacial de tais movimentos, a fim de que os participantes aprendam a esquematizar a tridimensionalidade do espaço e a esfericidade, no caso de representações da esfera celeste.

Outro princípio que poderia ser constatado e decorrente de observações do céu repetidas em diversos dias seguidos, ou de um ano para outro, está relacionado à ciclicidade do movimento da esfera celeste, o que o relaciona à ideia de tempo cíclico. Tal conceito ocorreria na volta da observação do panorama das estrelas, de uma noite para outra imediatamente seguinte, ou de tal repetição de um ano para outro.

Reitera-se que os resultados aqui apresentados e discutidos necessitam ser reaplicados para um grupo maior de professores, com o objetivo de se aprofundar, consolidar e enfrentar as diversas questões colocadas para o ensino de Astronomia, dentre elas, o importante tema da observação do céu.

\title{
Referências
}

BRETONES, P. S. Os segredos do universo. São Paulo: Atual, 1995.

\author{
A Astronomia na formação continuada de professores e o papel da \\ racionalidade prática para o tema da observação do céu. 2006. 187f. Tese (Doutorado \\ em Ensino e História de Ciências da Terra) - Instituto de Geociências, Universidade \\ Estadual de Campinas, Campinas, 2006.
}

CANIATO, R. O céu. São Paulo: Ática, 1990.

COMPIANI, M.; CARNEIRO, C. dal R. Os papéis didáticos das excursões geológicas. Enseñanza de las Ciencias de la Tierra, Madrid, v. 1, n. 2, p. 90-98, 1993. Disponível em: < http://www.raco.cat/index.php/ECT/article/view/88098/140821>. Acesso em: 19 mar. 2011.

CORDERO, S. O taller de enseñanza de física: inovações e pressupostos de uma proposta universitária de aprendizagem colaborativa. Ensaio: Pesquisa em Educação em Ciências, Belo Horizonte, v. 4, n. 1, p. 1-19, 2002. Disponível em: < http://www.portal.fae.ufmg.br/ seer/index.php/ensaio/article/view/45/363>. Acesso em: 4 mar. 2011.

CUSTÓDIO, J. F.; PIETROCOLA, M. Princípios nas ciências empíricas e o seu tratamento em livros didáticos. Ciência \& Educação, Bauru, v. 10, n. 3, p. 383-399, 2004. Disponível em: <www.scielo.br/pdf/ciedu/v10n3/06.pdf>. Acesso em: 19 mar. 2011.

LANCIANO, N. Ver y hablar como Tolomeo y pensar como Copérnico. Enseñanza de las Ciencias, Barcelona, v. 7, n. 2, p. 173-182, 1989. 
Evolução conceitual de professores ...

MOREIRA, M. A. Aprendizagem significativa: um conceito subjacente. In: ENCUENTRO INTERNACIONAL SOBRE EL APRENDIZAJE SIGNIFICATIVO, 2., 1997, Burgos.

Actas... Burgos (Espanha), 1997. p. 17-44. Disponível em: <www.if.ufrgs.br/ moreira/ apsigsubport.pdf $>$. Acesso em: 2 mar. 2011.

MOREIRA, M. A.; GRECA, I. M. Cambio conceptual: análisis critico y propuestas a la luz de la teoria del aprendizaje significativo. Ciência \& Educação, Bauru, v. 9, n. 2, p. 301-315, 2003. Disponível em: <http://www.if.ufrgs.br/ moreira/cambioconceptual. pdf $>$. Acesso em: 19 mar. 2011.

MOURÃO, R. R. F. Atlas celeste. 8. ed. Rio de Janeiro: Vozes, 1997.

PATY, M. A ciência e as idas e voltas do senso comum. Scientiae Studia, São Paulo, v. 1, n. 1, p. 9-26, 2003. Disponível em: <http://www.scielo.br/pdf/ss/v1n1/a01v1n1.pdf>. Acesso em: 19 mar. 2011.

Artigo recebido em 11/07/2010. Aceito em 23/01/2011. 